\title{
Modeling freshwater snail habitat suitability and areas of potential snail-borne disease transmission in Uganda
}

\author{
A.S. Stensgaard ${ }^{1,3}$, A. Jørgensen ${ }^{1}$, N.B. Kabatereine ${ }^{2}$, C. Rahbek ${ }^{3}$, T.K. Kristensen ${ }^{1}$ \\ ${ }^{1}$ Mandahl-Barth Research Centre for Biodiversity and Health in Developing Countries, DBL - Institute for \\ Health Research and Development, Charlottenlund, Denmark; ${ }^{2}$ Vector Control Division, Ministry of Health, \\ Kampala, Uganda; ${ }^{3}$ Center for Macroecology, Institute of Biology, University of Copenhagen, Denmark
}

\begin{abstract}
Geographic information system (GIS)-based modeling of an intermediate host snail species' environmental requirements using known occurrence records can provide estimates of its spatial distribution. When other data are lacking, this can be used as a rough spatial prediction of potential snail-borne disease transmission areas. Furthermore, knowledge of abiotic factors affecting intra-molluscan parasitic development can be used to make "masks" based on remotely sensed climatic data, and these can in turn be used to refine these predictions. We used data from a recent freshwater snail survey from Uganda, environmental data and the genetic algorithm for rule-set prediction (GARP) to map the potential distribution of snail species known to act as intermediate hosts of several human and animal parasites. The results suggest that large areas of Uganda are suitable habitats for many of these snail species, indicating a large potential for disease transmission. The lack of parasitological data still makes it difficult to determine the magnitude of actual disease transmission, but the predicted snail distributions might be used as indicators of potential present and future risk areas. Some of the predicted snail distribution maps were furthermore combined with temperature masks delineating suitable temperature regimes of the parasites they host. This revealed the coinciding suitable areas for snail and parasite, but also areas suitable for host snails, but apparently not for the parasites. Assuming that the developed models correctly reflect areas suitable for transmission, the applied approach could prove useful for targeting control interventions.
\end{abstract}

Keywords: snails, parasites, schistosomiasis, distribution, habitat modeling, remote sensing, geographic information system.

\section{Introduction}

In a recent malacological survey in Uganda, several freshwater snail species known to be important intermediate hosts of human and animal parasites were collected (Jørgensen, 2003). These included several Bulinus and Biomphalaria snail species known to act as intermediate hosts for the parasite Schistosoma sp., the cause of schistosomiasis in humans and other mammals. Also com-

Corresponding author:

Anna-Sofie Stensgaard

Mandahl-Barth Research Centre for

Biodiversity and Health in Developing Countries, DBL

Institute for Health Research and Development

Jægersborg Allé 1D, DK - 2920

Charlottenlund, Denmark

Tel. +45 773277 32; Fax +45 77327733

E-mail: asstensgaard@dblnet.dk monly encountered was Lymnaea natalensis, the intermediate host of Fasciola gigantica the cause of fascioliasis in wildlife, livestock and humans. Several of these snails also have the potential to host a number of amphistome species (stomach flukes), that cause serious infections in domestic livestock and wild grazing animals in Africa (Dinnik, 1964). However, like many other vectorborne diseases in the tropics and sub-tropics, parasitological survey data are scarce, rendering it difficult to assess the extent and magnitude of disease transmission. In general, the distributions of the snail-borne diseases depend largely on the spatial distribution of suitable intermediate host snails. However, it can be difficult to establish where transmission is likely to occur, based solely on the presence of suitable water bodies and intermediate host snails. There are areas where intermediate 
host snails occur, but there is no disease. Besides of course from human occupational and other socioeconomic related factors, the absence of disease in these areas could be due to unfavorable environmental conditions for parasite development. Such conditions could include too low or too high temperatures, which affect the metabolic processes of both the snail host and the parasite, thus interfering with parasite reproduction within the snail, snail growth and snail survival rate (Appleton, 1978). Thus, studies of such abiotic factors are useful because they give an indication of the suitability of the habitat as a potential transmission site. Temperature has been pointed to as the most important factor (Appleton, 1978) besides factors such as rainfall (water availability), water velocity, geomorphology and habitat stability (Appleton, 1978).

Recently, several approaches to predictive modeling of species' geographic distributions based on biotic and abiotic factors have been developed within a geographic information system (GIS) framework. Such modeling tools have been applied within a variety of fields such as biogeography, conservation, evolutionary ecology, invasive-species management and disease ecology (e.g. Carpenter et al., 1993; Jarvis and Robertson, 1999; Hay et al., 2000; Peterson et al., 2002; James and McCulloch, 2002, Estrada-Peña, 2002; Arriaga et al., 2004). One approach is ecologic niche modeling of primary occurrence data (data placing a particular species in a particular site) (Stockwell and Noble, 1992; Stockwell and Peters, 1999; Peterson and Vieglais, 2001). The approach involves a machine-learning algorithm for discovering associations between point occurrence data and remotely sensed maps summarizing environmental dimensions that may or may not be important in limiting species' distributions. These associations constitute an approximation of species' fundamental ecologic niches (MacArthur, 1972) and provide a basis for understanding ecologic and geographic phenomena related to species distributions.

The aims of the present study were: (i) to produce habitat suitability maps for snail species known to act as intermediate hosts for parasites in Uganda, and (ii) to identify suitable/unsuitable areas of disease transmission overlapping these host snail distribution ranges, based on knowledge of optimal temperature regimes for parasitic development in the snail.

Distribution maps indicating levels of habitat suitability for the snails were developed using the desktop version of the genetic algorithm for rule-set prediction (GARP) (Stockwell and Noble, 1992; Stockwell and Peters, 1999). The distribution maps are, where possible, discussed in the context of known parasite occurrence and distributions. If successful, the applied approach could prove a valuable tool to identify on a large scale, suitable areas for intermediate host and parasite species (for which detailed information is not available), and for planning the operational aspects of disease control interventions.

\section{Materials and methods}

\section{Snail occurrence point data}

Snail sampling was conducted in the period 2000 to 2003. Approximately 20,000 freshwater snail specimens were collected from 89 different sampling sites across Uganda. In addition to the larger lakes, a number of inland habitats were sampled, including swamps, temporal ponds, small lakes, rivers and streams. All sampling localities were geo-referenced using a hand-held global positioning system (GPS) (Trimble GeoExplorer II; Trimble Navigation Ltd., Sunnyvale, CA, U.S.A.). Other than Biomphalaria species (the intermediate host snail of Schistosoma mansoni), at least three other freshwater snail species groups and genera that are also intermediate hosts of parasites were identified. These were members of the Bulinus truncatus/tropicus species complex and the Bulinus africanus group (intermediate hosts of, among others, $S$. haematobium that cause urinary schistosomiasis), and the Bulinus forskalii 
group, intermediate hosts of $S$. intercalatum (Wright et al., 1972) and S. bovis (Southgate and Knowles, 1975). The gastropod species L. natalensis, the intermediate host of the liver fluke $F$. gigantica, that causes fascioliasis in both humans and animals throughout Africa (Mas-Coma et al., 1999), were also among frequently encountered snail species. A list of the snail species found in Uganda and the parasites they potentially host can be seen in Table 1 .

Due to unresolved taxonomic problems and difficulties with species determination, species belonging to the Bu. truncatus/tropicus complex are referred to the species complex and not the individual species throughout this paper. Snail species "Biomphalaria cf. pfeifferi" and Biomphalaria sudanica suggested to be responsible for inland transmission of intestinal schistosomiasis in Uganda are modeled together due to cur- rent taxonomical problems with the separation of the species. "Bi.cf. pfeifferi", conchologically looks like Bi. pfeifferi but are molecularly closely related to Bi. sudanica (Jørgensen, 2003). They are referred to in this paper as $B i$. "pfeifferi"/sudanica (see also Stensgaard et al., 2005 ), and are represented by a total of 44 individual point records. The distribution of species belonging to the $\mathrm{Bu}$. truncatus/tropicus complex were modeled together, due to difficulties with morphological species identification and unresolved taxonomic issues within these groups, (Jørgensen, 2003). Members of the Bu. africanus group were included as well, as they are important S. haematobium hosts. Together, they made up a total of 42 species records. The Bu. forskalii group was represented with 19 individual point records, $L$. natalensis with 54 point records and $B i$. choanomphala with 17 point records. Other

Table 1. Naturally infected intermediate snail hosts present in Uganda, and the parasites they potentially host (after Brown, 1994). Records of widespread parasite presence is indicated with $(++)$, reported individual cases with $(+)$. No presence confirmed or presence unknown is indicated with (-).

\begin{tabular}{|c|c|c|c|}
\hline Snail & Parasites & Main mammalian host & Uganda \\
\hline $\begin{array}{l}\text { Biomphalaria spp.: } \\
\text { Bi. "pfeifferi"/sudanica, } \\
\text { Bi. choanomphala, } \\
\text { Bi. stanleyi }\end{array}$ & $\begin{array}{l}\text { S. mansoni } \\
\text { S. rodhaini } \\
\text { Paramphistomum } \\
\text { sukari }\end{array}$ & $\begin{array}{l}\text { Man } \\
\text { Rodents } \\
\text { Livestock and wild grazing animals }\end{array}$ & $\begin{array}{r}++) \\
(+) \\
(-)\end{array}$ \\
\hline Bulinus spp.: & & & \\
\hline$\overline{\text { Bu. africanus group }}$ & $\begin{array}{l}\text { S. haematobium } \\
\text { S. bovis } \\
\text { S. mattheei } \\
\text { S. curassoni } \\
\text { S. intercalatum } \\
\text { S. leiperi } \\
\text { Echinostome spp. }\end{array}$ & $\begin{array}{l}\text { Man } \\
\text { Cattle } \\
\text { Cattle, sheep } \\
\text { Cattle, sheep } \\
\text { Man } \\
\text { Antelopes, cattle }\end{array}$ & $\begin{array}{l}(+) \\
(+) \\
(-) \\
(-) \\
(-) \\
(-)\end{array}$ \\
\hline $\begin{array}{l}\text { Bu.truncatus/tropicus } \\
\text { complex }\end{array}$ & $\begin{array}{l}\text { S. bovis } \\
\text { S. haematobium } \\
\text { S. margrebowiei } \\
\text { Calicophoron } \\
\text { microbotrium }\end{array}$ & $\begin{array}{l}\text { Cattle } \\
\text { Man } \\
\text { Antelopes, cattle } \\
\text { Livestock and wild grazing animals }\end{array}$ & $\begin{array}{l}(+) \\
(-) \\
(-)\end{array}$ \\
\hline Bu. forskalii group & $\begin{array}{l}\text { S. intercalatum } \\
\text { S. bovis } \\
\text { S. margrebowiei } \\
\text { Carmyerius sp. } \\
\text { P. phillerouxi }\end{array}$ & $\begin{array}{l}\text { Man } \\
\text { Man } \\
\text { Antelopes, cattle } \\
\text { Livestock and wild grazing animals } \\
\text { Livestock and wild grazing animals }\end{array}$ & $\begin{array}{r}(-) \\
(+) \\
(-) \\
(-) \\
(-)\end{array}$ \\
\hline$\frac{\text { Lymnaea spp.: }}{\text { L. natalensis }}$ & F. gigantica & Cattle, sheep & $(+)$ \\
\hline
\end{tabular}


known intermediate host snail species (e.g. Bi. stanleyi and $B i$. smithi) were not modeled due to lack of sufficient point records.

\section{Parasitological data}

The only currently available parasitological survey data from Uganda, comes from a recent epidemiological study of $S$. mansoni, conducted by the Vector Control Division, Ministry of Health Uganda in the period 1998-2002. Data is available from 201 georeferenced schools from across Uganda, including a total of 13,798 schoolchildren (Kabatereine et al., 2004). The dataset was divided into presence/absence data for endemic disease transmission at a particular site, using a cut-off value of $5 \%$ prevalence. This data set is used to validate the specificity and sensitivity of the final map of predicted suitable transmission areas for $S$. mansoni. No such data exist for any of the other parasites in Uganda.

\section{Snail distribution model development}

As environmental input data for ecological niche modeling in the present study, we chose environmental and climatic variables, suggested to be important for freshwater snail distributions. This included temperature and water availability proxies from satellite sensor land surface temperature (LST) products (day- and night-time) and normalized difference vegetation index (NDVI) (annual mean, wet and dry season) from the MODIS satellite sensor. A climate surface grid of monthly long-term climate data for the climatic normal period 1931-1960 (IGAD/Nile Minimum Medical Database (MMBd) (Malone et al., 2001) was also utilized. Furthermore, landscape characteristics such as altitude and slope (from a digital elevation model), distances from streams, major rivers, wetlands and lakes, and a vegetation map from the National Biomass Study Project (Ministry of Natural Resources, Kampala, Uganda, 1995) were included. GARP utilizes presence data only, rather than both presence and absence, which is the more general case. Hence, variability among GARP models (which is typical of genetic algorithms) and complications in interpreting results based on presence only input data make model selection critical (Anderson et al., 2003). The procedure for choosing the most optimal models in this paper thus follows the recommendations of Anderson et al. (2003). The 10 best models for each species were selected following these recommendations and criteria. The models were then summed in ArcGIS ${ }^{\circledR}$ version 8.3 (ESRI, Redlands, CA) creating a composite prediction in which the value for each map pixel corresponds to the number of models (1-10) predicting a species presence in that cell. The resultant composite map represents a density surface related to the probability of suitable environmental conditions for that particular species. GARP was set to run 100 times with a convergence limit of 0.01 and 200 maximum iterations. Besides from the internal evaluation procedures of the modeling programme itself, the performance (accuracy) of the snail distribution models was evaluated using Cohen's kappa (Cook, 1998), which includes absence records.

\section{Deriving transmission suitability maps based on temperature and snail distributions}

The intra-molluscan stages of transmission for many snail-borne parasitic diseases are often identified as the weakest link and most sensitive to the effects of temperature. Thus, after developing distribution maps for the host snail species, these were superimposed with temperature masks for the parasite species they host, to produce maps of suitable transmission areas. The temperature masks were developed using GIS query procedures on the MODIS LST layers based on experimentally established thermal maximum and minimum limits of the intra-molluscan development for $S$. mansoni, S. haematobium and F. gigantica. Areas that were found to be below the theoretical developmental null point for the parasite in the snail 
were identified from annual mean night-time (minimum) LST for both dry season and wet season, and excluded. These optimal temperature regime maps were then combined to produce one final temperature mask for each parasite species. The temperature regime used to create the $S$. mansoni temperature mask were $16-35^{\circ} \mathrm{C}$ with a developmental null point of $14.2^{\circ} \mathrm{C}$ (Pflüger, 1980, Joubert et al., 1986). A temperature regime of $18-32^{\circ} \mathrm{C}$ and a developmental null point of $15.3^{\circ} \mathrm{C}$ were used to mask out areas unsuitable for S. haematobium transmission (Pflüger et al., 1984). For F. gigantica a base life cycle development temperature of $16^{\circ} \mathrm{C}$ (Dinnik and Dinnik, 1963 ) and a thermal tolerance limit of $>36^{\circ} \mathrm{C}$ (Dinnik and Dinnik, 1963; Malone, 2005) was used to create the temperature mask.

\section{Results}

\section{Snail distribution models}

Distribution models were developed for five different snail species or species groups: Bi. "pfeifferi"/sudanica", Bi. choanomphala, Bu. truncatus/tropicus (and Bu. africanus), Bu. forskalii and L. natalensis. The resultant distributional maps can be seen in Fig. 1 (a-e).

The distribution maps produced by GARP indicate that Bi. "pfeifferi"/sudanica, (Fig. 1a), the main intermediate host snail of $S$. mansoni in inland areas in Uganda, and L. natalensis, (Fig. 1b) the first intermediate host of the liver fluke $F$. gigantica in Africa (Brown, 1994), have the widest distributions. The Bu. truncatus/tropicus and $B u$. africanus (Fig. 1c) also show a wide distribution, although the concordance between the 10 superimposed models is not as strong as with the former two. Only about half of the predicted areas are chosen by 9-10 models. The modeled distribution for the Bu. forskalii group (Fig. 1d) is more moderate and concentrated in the central areas of Uganda, along the eastern coastal areas of Lake
Victoria, and scattered fragmental areas in the south-western region of the country. For another $S$. mansoni intermediate host in Uganda, $B i$. choanomphala (Fig. 1e), suitable habitats were predicted at Lake Victoria margins, along the Victoria Nile, the Lake Kyoga margins, a few narrow strips at Lake Albert and some of the crater lakes in the south-western regions of Uganda. The GARP Bi. choanomphala model showed very good agreement between the model predictions and observed presence/absence data, with a kappa value of 0.76 (S.E. = 0.09). All other modeled freshwater gastropods showed a relatively poor agreement, with kappa values between 0.18 and 0.23 (S.E. $=0.05-0.06)$.

\section{Transmission suitability maps}

Superimposing the relevant snail distribution maps with the temperature masks for the parasites $S$. mansoni, S. haematobium and F. gigantica, revealed geographic areas where both snails and parasites are likely to co-exist, indicating the ecologically suitable transmission areas for each snail-borne disease. The resultant maps can be seen in Fig. 2.

In general, the snails appear to be restricted in their distribution in the northern parts of the country (dry and hot), whereas the parasites (based solely on temperature) seem to be restricted only in the south-western region which, according to the average annual LST maps, are too cold for their development.

Using the parasitological data on $S$. mansoni to evaluate the sensitivity of the developed transmission suitability map showed that $85.6 \%$ (95\% confidence interval $(\mathrm{CI})=84.4-87.7 \%$ ) of the positive disease data points were correctly identified by the predicted suitable transmission areas for intestinal schistosomiasis. The proportion of true negatives that were correctly identified by the model (negative disease points in unsuitable transmission areas) was $56.2 \%(95 \%$ CI $=55.1-58.5 \%)$. Thus the descriptive model for $S$. mansoni had a high sensitivity but only a moderate specificity. 

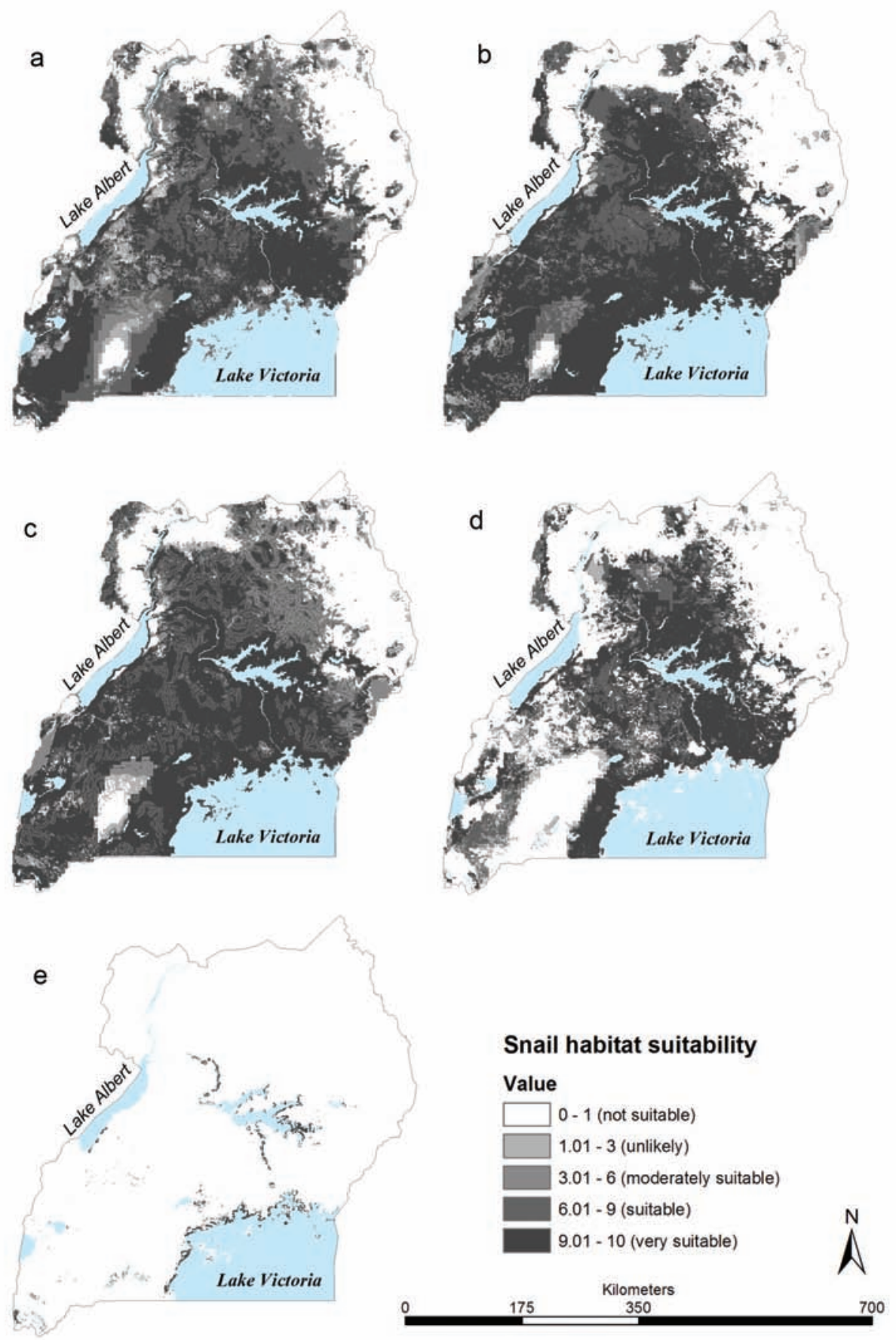

Fig. 1. Snail species distribution maps as modeled by GARP. a) Biomphalaria "pfeifferi"/sudanica, b) Lymnaea natalensis, c) Bulinus truncatus/tropicus complex including B. africanus, d) Bulinus forskalii group, e) Biomphalaria choanomphala. Numbers 1-10 indicate number of models, out of a total of 10 models, choosing a particular pixel as species presence. This is translated into an index of likely snail habitat suitability, with higher values indicating higher suitability. 


\section{Discussion}

Nearly all the modeled snail distributions indicate that substantial areas of Uganda are suitable habitats for intermediate host snails and thus potential risk areas for the parasites that they host during the asexual stage of the life cycle. In general, the areas predicted to be unsuitable habitats are the dry and hot areas of northern and north-eastern Uganda and for some of the snail species, also scattered parts of the cooler southwestern Uganda with low precipitation. The next step towards identifying suitable transmission areas for snail-borne diseases in Uganda was to overlay the snail distribution maps with a mask of suitable temperature regimes for the intra-molluscan parasite development. This revealed that, while the snail distributions were restricted in the north and north-eastern parts of Uganda (high temperatures, low precipitation/moisture), the distribution of the parasite was instead restricted in the southern and cooler parts of the country. This is in agreement with earlier observations that, while parasites are more sensitive to low temperatures than they are to high temperatures, the opposite is true for many of their snail hosts which do not withstand high temperatures well (Appleton, 1978). Only F. gigantica and its intermediate host snail L. natalensis show potential for transmission also in the southern areas of Uganda. Not surprisingly, this parasite has the largest overall transmission area. Fasciola parasites cause fascioliasis in herbivores, principally sheep and cattle, but have also been shown to be a widespread health problem for humans as well (MasComa and Bargues, 1997; Mas-Coma et al., 1999).

Today, based on estimates of up to 91 million infected humans globally (Keiser and Utzinger, 2005) fascioliasis must be considered an important human parasitic disease. Very few studies on the epidemiology of human and animal fascioliasis in Uganda exists, but according to an investigation of the potential distribution of F. gigantica in East Africa, emanating from Food and Agricultural Organization (FAO) databases, a large part of
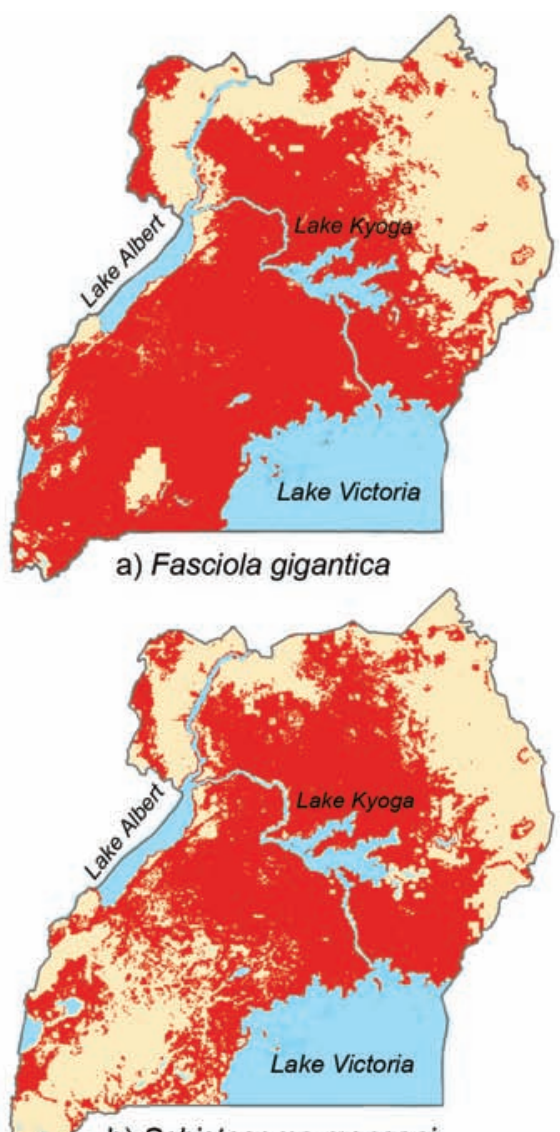

b) Schistosoma mansoni

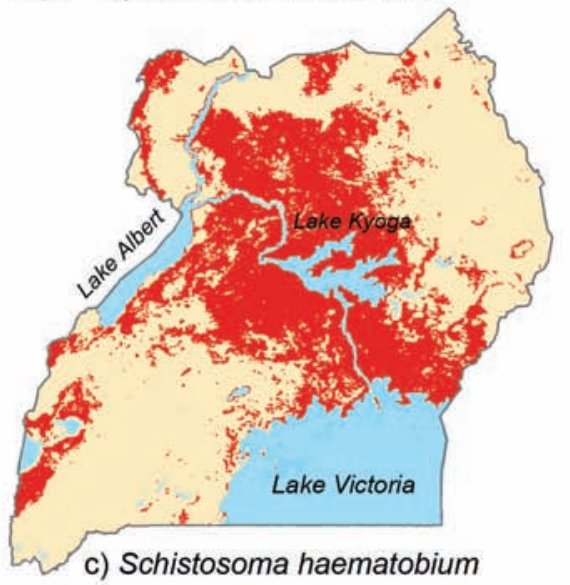

Fig. 2. Transmission suitability maps based on vector snail distributions and areas of suitable temperature regimes for parasite development in the host snail for a) $S$. mansoni (host snails Bi. "pfeifferi"/sudanica and Bi. choanomphala, b) $S$. haematobium (host snails $B u$. truncatus/tropicus and $B u$. africanus and c) F. gigantica (host snail L. natalensis). 
Uganda is at potential risk of the disease (Malone et al., 1998). There are reports of fascioliasis prevalence rates of $53.7 \%$ in livestock in Uganda (Ogambo-Ongoma, 1972) and reports of F. gigantica in African buffaloes and antelopes in Uganda (Bindernagel, 1972). Furthermore, there has been speculation about the part possibly played by wild African ruminants in the epidemiology of fascioliasis, both in relation to infection of domestic livestock and out of concern for the potential damage that fascioliasis could cause to wildlife confined within reserves (Hammond, 1972; Brown, 1994). A recent investigation (Ocaido et al., 2004) has shown that F. gigantica is one of the most widespread helminths among wildlife in and around Lake Mburo National Park in Uganda, confirming earlier reports by Hammond and Sewell (1993) and Okao (1975), that in Uganda F. gigantica can be maintained in wildlife without the presence of domestic livestock. The reports on Fasciola in both wildlife and livestock, combined with the large geographical areas of suitable $L$. natalensis habitat modeled for Uganda, indicate a potential human and livestock health risk, especially in areas around national parks were mixed game and livestock production systems exists (Ocaido et al., 2004). To evaluate the magnitude of human risk to fascioliasis in Uganda, epidemiological studies in areas overlapping with modeled suitable habitats for L. natalensis should be undertaken.

The snail distribution map for $B u$. truncatus/tropicus complex and Bu. africanus also show a wide distribution potential with similar ranges to those of $\mathrm{Bi}$. "pfeifferi"/sudanica. However, the temperature masks indicate a larger suitable transmission area for $S$. mansoni than for $S$. haematobium. The latter is reported to be found in the areas surrounding Lake Kyoga in central Uganda, were it co-exists with S. mansoni (Bradley et al., 1967) an area that lies in the midst of the predicted suitable transmission area. Why the disease is not more widespread in Uganda, given the apparently wide distribution of some of its host snail, remains to be investigated through expanded epidemiological surveys.

The distribution models, both for S. mansoni and its main intermediate host Bi. "pfeifferi"/sudanica, in inland Uganda showed a fairly wide potential distribution and was the only model that could be tested against readily available parasitological point data. It showed a high sensitivity in that the predicted suitable transmission areas were able to capture $85.6 \%$ of the schools in Uganda where the infection prevalence of $S$. mansoni was above $5 \%$. The specificity was however low as there were several schools with lower infection prevalences found within the predicted transmission area. However, considering the multi-factorial nature of the disease, the lack of a highly accurate diagnostic approach and an ongoing chemotherapy-based morbidity control programme, this is not unexpected. In fact, large variation in schistosomiasis prevalence between closely situated schools and communities is a well known phenomenon.

The Bu. forskalii group, host to $S$. bovis among others, seems to have a more restricted distribution than the other Bulinus species. Not much is known about the epidemiology of the parasite in Uganda as no complete epidemiological survey has been conducted. The first substantiated report of $S$. bovis comes from Lake Albert, western Uganda (Stothard et al., 2004). This area overlaps with modeled suitable host snail habitats. Further epidemiological surveys are needed to clarify the extent of bovine schistosomiasis, particularly since the lakeside plain where $S$. bovis was isolated has been earmarked for a future game reserve (Stothard et al., 2004).

In general, maps that reveal areas of both high probability of snail and parasite occurrence could be used to guide first-priority control interventions. In areas where snail habitat suitability apparently is low relative to disease transmission, other factors must play vital roles which should be taken into consideration when planning health interventions. Furthermore, seen in the context of limited resources for interventions, targeted snail control could focus on areas suitable for both par- 
asite and snail. However, given the risk of future climate change, attention should be given to snail distribution areas where parasites might not exist presently, as described in another original research paper in this issue of Geospatial Health, with an emphasis on Oncomelania hupensis, the intermediate host for S. japonicum (Yang et al., 2006).

Ecological niche modeling has been shown to be an interesting tool also for epidemiology (Peterson et al., 2002; Levine et al., 2004) However, as all other modeling approaches, it cannot make up for lack of sufficient and relevant data. Some of the developed models showed a relatively poor performance as measured by the kappa statistic. This relatively poor performance can be caused by several different factors. One obvious reason for the poor performance could be that the set of snail data is insufficient, both in terms of numbers of point records and lack of coverage in some areas. In addition, freshwater gastropods are generally elusive species that can be difficult to detect during snail sampling surveys. An alternative explanation could be a poor identification of snail species-specific abitat suitability, due to the unresolved taxonomy with in some of the groups modeled together as one "species". Furthermore, distributional GARP predictions may often include areas that are not inhabited by the species in question, resulting in a focus on ecological niches and potential geographic distributions instead of on actual geographic distributions (the realized niches of species). This would result in commission (overprediction) errors (Peterson and Vieglais, 2001). Errors in the prediction of species' distributional areas can also be due to algorithmic and biotic errors derived from model construction and data uncertainties (Fielding and Bell, 1997). Biotic errors are inevitable because the model is a simplification of reality and cannot include all of the environmental factors that influence the different species' distribution. Other environmental parameters, such as water temperature, oxygen content, $\mathrm{pH}$, stream flow, etc., potentially have a greater influence. Finally, the spatial scale or resolution of the model can also determine the patterns of association detected between the environmental variables and species presence/absence (Rahbek and Graves, 2000; Karl et al., 2000). Future studies should preferentially test the datasets with the newer but rarely used species distribution modeling methods, including machine-learning methods and community models which recently have been shown to outperform more established methods (Elith et al., 2006). Furthermore, Bayesian geostatistical analysis, incorporating uncertainty into the modeling process, has recently proven a powerful and statistically robust tool for identifying high schistosomiasis prevalence areas in a heterogeneous and imperfectly known environment, an approach that enables objective decisions to be taken as to the need for further data collection (Raso et al., 2005; Clements et al., 2006).

The approach employed in the current study provides quantitative, operational estimates of a species' geographic range that gives insight into the biology and ecology of both the snail and parasite species, and would primarily be primarily useful for intermediate host snail management. In addition the maps can be used to guide productive fieldwork, through identification of e.g. areas of low disease risk, but high probability of sustaining host snails. These areas might presently be unsuitable for the parasite, but could become important new transmission areas under environmental change scenarios, including global warming as articulated above.

Because of the numerous sources of uncertainty in the modeling process, it is vitally important to test the output predictions of any model but a meaningful validation can often be difficult to carry out due to lack of truly independent test datasets (Elith et al., 2006). One step towards improving the evaluation of model performance in predicting species' distribution is to use independent, well-structured presence/absence datasets for validation (Elith et al., 2006). However, as in the study presented here, this type of data set often does not exist. In the end, the choice of spatial 
scale, environmental predictor variables (Guisan and Zimmerman, 2000) and the representation of environmental relationships within a model all reflect assumptions by the modeler. Regardless of the conceptual assumptions, the cost efficiency and rapid development of species predictive models make them useful for large-scale prediction. It should, however, be stressed that modeling never can provide a complete substitute for detailed, continued collection of field data.

\section{Acknowledgements}

The authors wish to thank the Vector Control Division, Ministry of Health, Uganda, for supporting the publication of this paper and for the logistic assistance provided by many of the staff members in connection with the snail sampling. The study was supported by grants from 'WWF Verdensnaturfonden/Novo Nordisk Biodiversitetslegatet', the VILLUM KAHN RASMUSSEN Foundation and the Danish Development Research Council.

\section{References}

Anderson RP, Lew D, Peterson AT, 2003. Evaluating predictive models of species' distributions: criteria for selecting optimal models. Ecol Modell 162, 211-232.

Appleton CC, 1978. Review of literature on abiotic factors influencing the distribution and life cycles of bilharziasis intermediate host snails. Malacol Rev 11, 1-25.

Arriaga L, Castellanos AE, Moreno E, Alarcón J, 2004. Potential ecological distribution of alien invasive species and risk assessment: a case study of buffel grass in arid regions of Mexico. Conservation. Biology 18, 15041514.

Bindernagel BA, 1972. Liver fluke Fasciola gigantica in African buffalo and antelopes in Uganda, East Africa. J Wildl Dis 8, 315-317.

Bradley D, Sturrock RF, Williams PN, 1967. The circumstantial epidemiology of Schistosoma haematobium in Lango District, Uganda. East Afr Med J 44, 193-204.

Brown DS, 1994. Freshwater snails of Africa and their medical importance, $2^{\text {nd }}$ Ed. Taylor and Francis, London, 608 pp.

Carpenter G, Gillison AN, Winter J, 1993. DOMAIN: a flexible modelling procedure for mapping potential distributions of plants and animals. Biodivers Conserv 2, 667-680.

Clements AC, Lwambo NJ, Blair L, Nyandindi U, Kaatano G, Kinung'hi S, Webster JP, Fenwick A, Brooker S, 2006. Bayesian spatial analysis and disease mapping: tools to enhance planning and implementation of a schistosomiasis control programme in Tanzania. Trop Med Int Health 11, 490-503.

Cook RJ, 1998. Kappa. In: Armitage TP, Colton (Eds). The Encyclopedia of Biostatistics, Wiley New York, 21602166 pp.

Dinnik JA, 1964. Intestinal paramphistomiasis and P. microbothrium Fischoeder in Africa. Bull Epizoot Dis Afr 12, 439-454.

Dinnik JA, Dinnik NN, 1963. Effects of seasonal variations of temperature on development of Fasciola gigantica in the snail host in the Kenyan highlands. Bull Epizoot Dis Afr 11, 197-207.

Elith J, Graham CH, Anderson RP, Dudík M, Ferrier S, Guisan A, Hijmans RJ, Huettmann F, Leathwick JR, Lehmann A, Li J, Lohmann LG, Loiselle BA, Manion G, Moritz C, Nakamura M, Nakazawa Y, Overton JM, Peterson AT, Phillips SJ, Richardson K, Scachetti-Pereira R, Schapire RE, Soberón J, Williams S, Wisz MS, Zimmerman NE, 2006. Novel methods improve prediction of species' distributions from occurrence data. Ecography 29, 129151.

Estrada-Peña A, 2002. Increasing habitat suitability in the United States for the tick that transmits Lyme disease: A remote sensing approach. Environ Health Perspect 110, 635-640.

Fielding AH, Bell JF, 1997. A review of methods for the assessment of prediction errors in conservation presence/absence models. Environ Conserv 24, 38-49.

Guisan A, Zimmerman NE, 2000. Predictive habitat distribution models in ecology. Ecol Modell 135, 147-186.

Hammond JA, 1972. Infections with Fasciola spp in wildlife in Africa. Trop Anim Health Prod 4, 1-13.

Hammond JA, Sewell MMH, 1993. Applied Helminthology for Diploma/Msc Students in Tropical Medicine. Centre for Tropical Veterinary Medicine, Edinburgh.

Hay SI, Randolph SE, Rogers DJ (Eds), 2000. Remote 
Sensing and Geographical Information Systems in Epidemiology. Adv Parasitol 47, 1-353.

James FC, McCulloch CE, 2002. Predicting species presence and abundance. In: Scott JM, Heglund PJ, Morrison ML, Haufler JB, Raphael MG, Wall WA, Samson FB (Eds.), Predicting Species Occurrences: Issues of Accuracy and Scale. Island Press, Washington, DC, pp. 461-465.

Jarvis AM, Robertson A, 1999. Predicting population sizes and priority conservation areas for 10 endemic Namibian bird species. Biol Conserv 88, 121-131.

Joubert PH, Pretorius SJ, de Knock KN, van Eeden JA, 1986. Survival of Bulinus africanus (Krauss), Bulinus globosus (Morelet) and Biomphalaria pfeifferi (Krauss) at constant high temperatures. S Afr J Zool 21, 85-88.

Jørgensen A, 2003. Diversity and phylogeny of African freshwater gastropods with special emphasis upon the molecular phylogeny of "ancyloplanorbidae" and Biomphalaria and snail biodiversity within the Great East African Lakes. $\mathrm{PhD}$ Thesis to the Faculty of Science, University of Copenhagen, 117 pp.

Kabatereine NB, Brooker S, Tukahebwa EM, Kazibwe F and Onapa A, 2004. Epidemiology and geography of Schistosoma mansoni in Uganda: implications for planning control. Trop Med Int Health 9, 372-380.

Karl JW, Heglund PJ, Garton EO, Scott JM, Wright NM, Hutto RL, 2000. Sensitivity of species habitat-relationship model performance to factors of scale. Ecol Appl 10, 1690-1705.

Keiser J, Utzinger J, 2005. Emerging Foodborne Trematodiasis. Emerg Infect Dis 11, 1570-1514.

Levine RS, Peterson AT, Benedict MQ, 2004. Geographic and ecologic distribution of the Anopheles gambiae complex using a genetic algorithm. Am J Trop Med Hyg 70, 105-109.

MacArthur RH, 1972. Geographical Ecology: Patterns in the Distribution of Species. New York: Harper and Row, 269 pp. Malone JB, Gommes R, Hansen J, Yilma JM, Slingenberg J, Snijders F, Nachtergaele F, Ataman E, 1998. A geographic information system on the potential distribution and abundance of Fasciola hepatica and F. gigantica in east Africa based on Food and Agriculture Organization databases. Vet Parasitol 78, 87-101.

Malone JB, McCarroll JC, Kristensen TK, Yilma JM, Erko B, El-Bahy MM, Corbett JD, 2001. Minimum Medical Database Spatial Decision Support System for the Inter Governmental Authority on Development-Nile Basin
Region (IGAD/Nile), 49 pp.

Malone JB, 2005. Biology-based mapping of vector-borne parasites by Geographic information systems and remote sensing. Parassitologia 47, 27-50.

Mas-Coma S, Bargues MD, 1997. Human liver flukes: a review. Res Rev Parasitol 57, 145-218.

Mas-Coma S, Esteban JG, Bargues MD, 1999. Epidemiology of human fascioliasis: a review and proposed new classification. Bull World Health Organ 77, 340-346.

NBSP (National Biomass Study Project), 1995 Technical Report National Biomass Study. Forestry Department. Ministry of Natural Resources, Kampala, Uganda.

Ocaido M, Siefert L, Baranga J, 2004. Helminth risk associated with mixed game and livestock interactions in and around Lake Mburo National Park, Uganda. Afr J Ecol 42, 42-49.

Ogambo-Ongoma AH, 1972. Fascioliasis survey in Uganda. Bull Epizoot Dis Afr 20, 35-41.

Okao AK, 1975. Bovine Fascioliasis in Uganda. Incidence and Economic Losses. Animal Health Research Center, Entebbe, Uganda.

Peterson AT, Vieglais DA, 2001. Predicting species invasions using ecological niche modeling: new approaches from bioinformatics attack a pressing problem. Bioscience 51, 363-371.

Peterson AT, Sanchez-Cordero V, Beard CB, Ramsey JM, 2002. Ecologic niche modeling and potential reservoirs for Chagas disease, Mexico. Emerg Inf Dis 8, 662-667.

Pflüger W, 1980. Experimental epidemiology of schistosomiasis I. The prepatent period and cercarial production of Schistosoma mansoni in Biomphalaria snails at various constant temperatures. Z Parasitenkd 63, 159-169.

Pflüger W, Roushdy MZ, El Eman M, 1984. The prepatent period and cercarial production of Schistosoma haematobium in Bulinus truncatus (Egyptian field strains) at different constant temperatures. Z Parasitenkd 70, 95-103.

Rahbek C, Graves GR, 2000. Detection of Macro-ecological Patterns in South American Hummingbirds is Affected by Spatial Scale. Proc Biol Sci London 267, 2259-2265.

Raso G, Matthys B, N'Goran EK, Tanner M, Vounatsou P, Utzinger J, 2005. Spatial risk prediction and mapping of Schistosoma mansoni infections among schoolchildren living in western Côte d'Ivoire. Parasitology 131, 97-108.

Stockwell DRB, Noble IR, 1992. Induction of sets of rules from animal distribution data: A robust and informative 
method of analysis. Math Comput Simul 33, 385-390.

Stockwell DRB, Peters DP, 1999. The GARP modelling system: Problems and solutions to automated spatial prediction. Int J Geogr Inform Syst 13, 143-158.

Stockwell, DRB, Peterson AT, 2002. Effects of sample size on accuracy of species distribution models. Ecol Modell 148, 1-13.

Stothard JR, Lockyer AE, Kabatereine NB, Tukahebewa E, Kazibwe F, Rollinson D, Fenwick A, 2004. Schistosoma bovis in western Uganda. J Helminthol 78, 281-284.

Southgate VR, Knowles RJ, 1975. The intermediate hosts of Schistosoma bovis in western Kenya. Trans R Soc Trop Med Hyg 69, 356-357.
Stensgaard A, Jørgensen A., Kabatereine NB, Malone JB, Kristensen TK, 2005. Modeling the distribution of Schistosoma mansoni and host snails in Uganda using satellite sensor data and Geographical Information Systems. Parassitologia 47, 93-103.

Wright CA, Southgate VR, Van Wijk HB, Moore PJ, 1972. What is Schistosoma intercalatum. Trans R Soc Trop Med Hyg 66, 20-64.

Yang G, Vounatsou P, Tanner M, Zhou X, Utzinger J, 2006. Remote sensing for predicting potential habitats of Oncomelania hupensis in Hongze, Baima and Gaoyou lakes in Jiangsu province, China. Geospatial Health 1, present issue. 